Virtuelle Räume

Herausgegeben von Elisabeth Vavra 



\section{Virtuelle Räume}

Raumwahrnehmung und Raumvorstellung im Mittelalter

Akten des 10. Symposiums des

Mediävistenverbandes, Krems, 24.-26. März 2003

Herausgegeben von Elisabeth Vavra

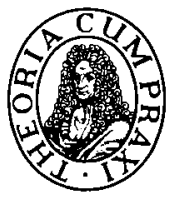

Akademie Verlag 
Abbildung auf dem Einband:

Der Makrokosmos

Liber Scivias der Hildegard von Bingen, Visio I, 3

Lopie des Rupertsberger Kodex

Abtei St. Hildegard Eibingen

ISBN 3-05-004129-3

c) Akademie Verlag GmbH, Berlin 2005

Das eingesetzte Papier ist alterungsbeständig nach DIN/ISO 9706.

Alle Rechte, insbesondere die der Übersetzung in andere Sprachen, vorbehalten. Kein Teil des Buches darf ohne Genehmigung des Verlages in irgendeiner Form - durch Fotokopie, Mikroverfilmung oder irgendein anderes Verfahren - reproduziert oder in eine von Maschinen, insbesondere Datenverarbeitungsmaschinen, verwendbare Sprache übertragen oder übersetzt werden.

Einbandgestaltung: Ingo Scheffler, Berlin Druck: MB Medienhaus Berlin

Bindung: Norbert Klotz, Jettingen-Scheppach

Printed in the Federal Republic of Germany 